\title{
Literatura y guerra. Elementos de una poética de la escucha en la obra Desterrados: crónicas del desarraigo, de Alfredo Molano*
}

Literature and War. Elements of a Poetics of Listening in Alfredo Molano's Work, Desterrados: crónicas del desarraigo

Michelle Camila Pérez Cardozo** Universidad de Tubinga, Alemania https://orcid.org/0000-0002-8600-0559

Artículo de investigación

Fecha de recepción: 16 de septiembre de 2019

Fecha de aceptación: 25 de octubre de 2019

\section{Para citar este artículo}

Pérez Cardozo, M. C. (2020). Literatura y guerra. Elementos de una poética de la escuchaen la obra Desterrados: Crónicas deldesarraigo, deAlfredoMolano. Camposen Ciencias Sociales, 8(1), 205-230. Dor: https://doi.org/10.15332/25006681/5720

* Artículo basado en la tesis de Maestría en Literaturas Internacionales de la Universidad de Tubinga, Alemania: Literatur und Krieg: Elemente einer Poetik des Zuhörens im Werk "Desterrados. Crónicas del desarraigo" von Alfredo Molano, aprobada en el semestre de invierno 2016-2017.

** Magíster en Literaturas Internacionales de la Eberhards Karl Universität Tübingen. Correo electrónico: michellec.perezc@gmail.com 


\section{Resumen}

A partir de la cuestión por la relación entre la guerra y la literatura, y tomando como referente a la literatura alemana de la posguerra, el presente artículo gira en torno a la función de la literatura en el contexto del posacuerdo en Colombia. Desde una mirada en la escritura de Alfredo Molano, sus alcances y propuesta poética, el objetivo de este artículo es analizar las representaciones del destierro y de la violencia en su libro Desterrados. Crónicas del desarraigo. A partir del enfoque de los estudios literarios inscrito en los debates actuales de la literatura de la violencia, el alcance de este análisis consiste en iluminar las potencialidades de su obra en la construcción de paz en el país.

Palabras clave: literatura y guerra, memoria, testimonio, poética de la escucha, Alfredo Molano.

\section{Abstract}

Starting from the question of the relationship between literature and war, and taking German post-war literature as a reference, this article revolves around the function of literature in the context of the post-agreement in Colombia. Focusing on Alfredo Molano's writing, its scope and poetic proposal, the aim of this article is to present the author's poetics by focusing the analysis on the representations of exile and violence in his book Desterrados. Crónicas del desarraigo (Exiled. Chronicles of Unrooting). Taking the approach of literary studies inscribed in the current debates on testimonial literature, the aim of this paper is to analyse the elements that constitute this poetics and to illuminate the potentialities of Molano's work in the construction of peace in the country.

Keywords: literature and war, memory and memories, witnessing, poetics of listening, Alfredo Molano. 
Creo, con ellos [los desterrados], que solo un acuerdo político profundo permitirá echar las bases de una verdadera democracia; la guerra no tendría resultado distinto a la dictadura de los vencedores.

Alfredo Molano, Desterrados (2001, p. 26) ${ }^{1}$

\section{INTRODUCCIÓN}

Colombia atraviesa un momento histórico en la actualidad con la implementación del acuerdo de paz pactado entre el Gobierno y la guerrilla de las Farc en noviembre de 2016. Este panorama, como ya se está viendo a diferentes escalas, no trae consigo el fin de la violencia, de la discrepancia de opiniones o de las profundas desigualdades sociales, sino que ofrece un escenario en el que se pueda plantear la posibilidad de tramitar estas diferencias de otra manera. La paz implica un gran desafío para Colombia, pues por décadas la sociedad ha aprendido a gestionar los conflictos por medios violentos, modo de proceder que se ha arraigado en la mentalidad de la población. Por esto, los acuerdos de paz deberían significar una nueva oportunidad para que la población desarrolle una conciencia distinta al afrontar sus conflictos de manera no violenta y recupere la exigencia legítima de sus derechos por vías democráticas.

Dado que la literatura ha tematizado el conflicto armado desde sus comienzos y desde diversos ángulos, más que describir esas narraciones, el presente escrito pregunta por la función que puede cumplir para la sociedad la existencia de tal literatura. A continuación, se defenderá la tesis según la cual el arte y la literatura pueden servir como un medio para el fomento de una conciencia de la solución pacífica de los conflictos, además de crear posibilidades de la superación de un pasado traumático. En este sentido, la literatura puede contribuir a la contrucción de una cultura de la memoria, que reconoce a las víctimas de la violencia y sus memorias,

1 El presente artículo fue aprobado en la semana del fallecimiento de Alfredo Molano. Siendo consciente del significado de esta pérdida para el país, espero que este escrito sirva de homenaje a su obra, contribuya a la difusión de la esta y dé lugar a distintas lecturas de sus libros, que posibiliten nuevos diálogos de camino a la paz. 
como también al esclarecimiento de los sucesos del conflicto armado y sus causas en el país entero. En vista de la formación de una cultura de paz, específicamente el artículo se centrará en el papel que la literatura de Alfredo Molano pueda jugar para las víctimas: ¿ofrece esta posibilidades de reconciliación, superación del trauma y reconstrucción de la estructura social? Para esclarecer la respuesta a estas preguntas se abordará como primera medida la relación entre la literatura y la guerra con referencia a la experiencia de la literatura alemana de la posguerra; luego, se presentarán los elementos particulares de la obra de Alfredo Molano, su estrecha relación con el conflicto armado y posible rol en el posacuerdo. Finalmente, se dirigirá la atención a su poética de la escucha ${ }^{2}$ concretamente en su libro de crónicas Desterrados: crónicas del desarraigo.

\section{LA LITERATURA Y LA GUERRA}

La relación entre literatura y guerra es crucial para considerar el papel que la primera juega en un contexto de posguerra, como lo fue después de la Segunda Guerra Mundial, y relevante para analizar el escenario colombiano del posacuerdo. Antes de aproximarse a esta relación, el análisis partirá de la pregunta por el arte y la literatura en la vida humana: ¿qué importancia tiene la literatura en la vida de los seres humanos?, ¿cuál es su función?, y ¿qué funciones puede cumplir en un contexto de guerra? Con estas preguntas recurrimos a la contundente respuesta del escritor austriaco Ernst Fischer, quien afirma que el arte es imprescindible para la vida de los seres humanos, pues sirve de medio que posibilita la cohesión de los seres humanos con su entorno, ya que estos se encuentran limitados por su individualidad, imperfección y por su carácter transitorio. Así, le confiere al arte la función inaugural de "conmover al ser humano por completo, posibilitar la participación del yo en una existencia y destino ajeno, potenciarlo para identificarse con el otro, para adentrarse en lo que no es y sin embargo puede llegar a ser" (Fischer, 1967, p. 17) ${ }^{3}$. De esta

2 Óscar Torres Duque (1998), en su artículo "Violencia y narración en Alfredo Molano", señala inicialmente la presencia de una poética en la obra de Molano, que, según él, se deja deducir de la elaboración narrativa de los testimonios recogidos por el autor.

3 Traducción propia. 
manera, el arte les confiere a las personas el poder mágico de traspasar las fronteras de la propia experiencia, ampliándola y abriendo posibilidades de comprensión y transformación del mundo (Fischer, 1967).

Heidegger también propone en su ensayo "El origen de la obra del arte" (2001) un papel fundante para el arte en la vida de los seres humanos, pues su esencia constituye transmitirle la verdad al existente. Para este, la obra de arte pone de manifiesto un mundo, es decir, hace que los seres humanos sean conscientes de su existencia y posición en medio de los otros seres existentes. Las cosas y los acontecimientos nos muestran su verdad al convertirse en arte, al ser poetizados (Dichtung ${ }^{4}$ ). El arte nos acerca a la verdad, "no es un adorno que acompaña la existencia humana, ni solo una pasajera exaltación ni un acaloramiento y diversión” (Heidegger, 2001, p. 139), parte de la condición del hombre, quien se reúne sobre la base de su existencia. En esta dirección, Heidegger da un paso más hacia adelante y le da una atención especial a la poesía (Poesie), pues para él esta goza de un puesto extraordinario en la totalidad de las artes, se encuentra en su centro. La denominaba arte por excelencia, partiendo de que su "materia prima que sobresale en la potencia del mundo de la obra" (Heideger, 2001, p. 79) es el lenguaje, las palabras mismas, que determinan la humanidad del ser humano, aquello que le es más propio.

En este contexto, la poesía -y la literatura por extensión- asume un rol fundamental, no solo de ser vehículo de expresión de belleza, sino porque en realidad es la que hace posible el lenguaje. Schadewaldt (1967) afirma que el "mundo de lo mágico" corresponde a la esfera del origen de la poesía y del lenguaje; las palabras eran originariamente metáforas de la realidad e hicieron al principio posible la comprensión fundamental del mundo y su verdad. Así, les ha posibilitado la literatura a los seres humanos, tanto la propia afirmación en el mundo y el reconocimiento de los otros desde el lenguaje, como una relación mágica con lo divino. En palabras de Heidegger, la poesía se convierte en una "proyección hacia lo divino/infinito como compensación a la finitud del hombre” (Heidegger, 2001, p. 31), pues por medio de esta los seres humanos han podido persistir en el tiempo y consolarse ante la muerte.

4 Heidegger hace referencia a la palabra Dichtung como creación artística y a Poesie como poesía. 
De este modo la función inicial de los poetas era sagrada, ya que ellos eran los encargados de cuidar aquella relación entre las personas y lo divino/infinito. Sin embargo, esta relación y la función del arte y la literatura en la sociedad han sufrido una ruptura, debido a que su carácter esencial ha pasado a un segundo plano en el mundo dominado por la técnica y la ciencia. Este proceso es aclarado por Schadewaldt (1967) como un "exilio interno" al que la palabra de la poesía ha sido confinada. El mythos como el ámbito de la poesía, donde se da la representación de la inagotable complejidad de relaciones entre el ser humano y el mundo, ha sido relegado, mientras que las esferas de la vida humana han sido dominadas por la palabra del logos, aquel campo donde la exactitud de las ciencias naturales y de la técnica, por medio de su demostración precisa de los fenómenos, abarca las explicaciones del mundo.

Una de las consecuencias de este dominio del logos en la vida humana se hace patente en la implementación de los adelantos técnicos en las guerras a comienzos de la era industrial. Si bien las guerras han hecho parte desde siempre de la historia de la humanidad, fue a partir de la Primera Guerra Mundial, cuyos excesos en crueldad no tenían precedentes, que con base en los avances científicos y técnicos se pudo implementar armas de destrucción masiva. Esto condujo a dimensiones de destrucción y de muerte inimaginadas.

Luego de partir con una función originaria esencial del arte y la literatura en la vida humana, retomamos la relación propuesta entre literatura y guerra. Los escritores que se han visto afectados directamente por las guerras se ocupan de sus sucesos desde diferentes perspectivas; para algunos la literatura sirve de refugio frente a las atrocidades de la guerra, para otros es instrumento de resistencia y de afirmación de las propias convicciones. También puede ser considerada como una oportunidad para dar testimonio, generar procesos de memoria de la propia experiencia o la de otros y así construir memoria colectiva.

En el contexto alemán posterior a la Segunda Guerra Mundial, muchos artistas y escritores se vieron confrontados con la violencia de la guerra y se dedicaron a la tarea de dar respuesta a la pregunta de si el arte y la literatura eran posibles después de Auschwitz. Cuenta de ello la da la compilación de escritos de diferentes artistas 
y escritores en el libro de Kadaisch: Lyrik nach Auschwitz? Adorno und die Dichter (2012) (¿Lirica después de Auschwitz? Adorno y los poetas).

Especialmente ellos se preguntaron cómo debía reaccionar la literatura frente a la catástrofe, cuál era su sentido después de la guerra y si el arte en realidad debiera dedicarse a estos temas. La respuesta a estas preguntas fue controvertida y una de las que más causó polémica fue la afirmación de Adorno, quien declaró que escribir poemas después de Auschwitz sería un acto de barbarie, frase de la que, sin embargo, años después se retractaría. La afirmación fue malentendida como una prohibición y del mismo modo refutada por poetas como Paul Celan y Nelly Sachs. Del mismo modo, fue interpretada como una provocación o una puesta en duda al trabajo de los escritores, cuyas réplicas se centraron en la legitimación de la escritura, la defensa del poema y, sobre todo, el sentido de la literatura en general.

La mayoría de las reflexiones de los escritores de la posguerra frente a los cuestionamientos hechos a la literatura coinciden en que "la literatura tiene que seguir existiendo"5 y solo en conciencia de Auschwitz (Kiedaisch, 2012, p. 20) el arte literario debería convertirse en un instrumento que sirviera para combatir el olvido y la negación de la responsabilidad de la sociedad en los hechos. En este contexto surge la exigencia de corresponsabilidad y de análisis crítico sobre el horror, es decir, los artistas se hicieron conscientes de la importancia de tratar el tema de la guerra para contribuir al esclarecimiento y superación de los sucesos de ella. Después de su veredicto, inclusive Adorno proclamó el compromiso ético de los artistas con la catástrofe, "porque, aunque el mundo ha sobrevivido a su propio hundimiento, necesita del arte como su inconsciente historiografía. Los artistas auténticos del presente son aquellos en cuyas obras se estremece aún el máximo horror" (Adorno, 2012, p. 53) ${ }^{6}$.

Para Geoffrey Hartman, uno de los investigadores de los procesos de construcción de memoria sobre el Holocausto, la función de la literatura en un contexto de guerra

5 Traducción propia.

6 Traducción propia. 
es crucial, pues esta opera como un medio que es más resistente que la memoria individual, y garantiza no solo la construcción de la memoria colectiva, sino también la preservación de las memorias sobre la guerra. El filólogo indica además que la función de la literatura en un contexto de guerra - como escritor o como lectorno es solamente activar la función estética del arte con el juego de las facultades de la imaginación del espectador/lector, sino que su tarea es también la de limitar esta función y por medio de su función ética, provocar un tipo especial de compasión (Hartman, 2000).

Este componente ético lo encontramos en los postulados de Ulrich Baer (2000), el compilador del trabajo Niemand zeugt für den Zeugen (Nadie testimonia por el testigo), reunión de ensayos sobre el testimonio y la cultura de la memoria sobre el Shoah, quien sugiere que la literatura a través del testimonio asume una función colectiva, la responsabilidad histórica de consignar la memoria de las víctimas, de ser su testigo para que las siguientes generaciones asuman la responsabilidad que conlleva ser testigos de los testigos, conocer de voz de las víctimas de los crímenes perpetuados por el nacionalsocialismo. El objetivo del trabajo por la memoria es un llamado a la corresponsabilidad conjunta de la sociedad, lo que se hoy se traduce en la defensa de los derechos de las minorías por parte de las mayorías, argumento que le confiere también una dimensión política al arte. De este modo, dicha función colectiva consigna la memoria del pasado atroz y al mismo tiempo serviría de elemento para la denuncia de los hechos no esclarecidos. La segunda función crucial que asume la literatura podría calificarse como terapeútica, ya que, como testimonio de carácter individual, les ofrece a las víctimas la posibilidad de reivindicarse con su pasado, pues por medio de la narración de los hechos de la guerra se puede llegar a superar el trauma vivido (Laub, 2000).

Estas reflexiones sobre el sentido del arte y de la literatura en el contexto de posguerra sirven entonces de puente con la realidad colombiana. Aunque se trate de contextos históricos, políticos, sociales y geográficos tan diferentes, la experiencia alemana es un referente frente al trabajo por la memoria en Colombia, dado que la guerra, así como las experiencias humanas del trauma y la muerte, son universales. La literatura alemana de la posguerra puede ayudarnos a iluminar el papel de la literatura colombiana en el posacuerdo. Así, se plantea la pregunta por los alcances de los procesos de una 
cultura de la memoria después del Holocausto para evitar actuales conflictos a gran escala. Los puntos de vista de los escritores y pensadores alemanes de la posguerra deberían contribuir a dilucidar el debate en Colombia sobre la importancia del arte en el posacuerdo y a demandar la exigencia irrevocable de no repetición de los hechos atroces. Como en el debate sobre el arte y la literatura después de Auschwitz se afirmó, en la cultura y la historia hay un antes y un después de Auschwitz (Schnurre, 2000, p. 125). Los sucesos de la Segunda Guerra Mundial, tanto en los campos de batalla como en la persecución masiva de judíos y minorías por los nazis, hacen parte de la historia de la humanidad y es necesario que permanezcan en la memoria de la humanidad en general. Esta catástrofe, que puede ser calificada como una de las más grandes tragedias de la historia humana, plantea preguntas esenciales y universales sobre el futuro de los seres humanos y la posibilidad de vivir unos junto a otros en el mundo a pesar de las profundas diferencias entre pueblos. Plantear estas preguntas en el escenario colombiano es un imperativo para la construcción de una sociedad pacífica.

Dado que Colombia, desde su consolidación como república en el siglo XIX, ha sido un territorio en el que se han presentado guerras constantemente y el conflicto armado con la guerrilla de las Farc, cuyo fin fue pactado en 2016, es considerado uno de los más largos de la historia del continente, tanto el arte como la literatura colombiana se han visto marcados por la violencia e innumerables obras de arte la han tematizado en sus diversas dimensiones. En el curso de la historia han existido numerosas iniciativas de artistas, escritores, académicos, pero también de la sociedad civil y de las víctimas del conflicto, quienes han emprendido esfuerzos para construir una memoria colectiva de los sucesos, inclusive mucho antes de los diálogos de paz de La Habana. En medio de condiciones desfavorables, han logrado producir sus trabajos (por ejemplo, censurados, perseguidos o amenazados), aunque muchas veces generan poco impacto en la sociedad y permanecen desconocidos para la mayoría de la población.

Desde distintos enfoques los escritores colombianos han buscado dar cuenta de los sucesos de la guerra en la sociedad; a través del arte ha sido posible mostrar versiones diferentes de los acontecimientos del conflicto que se diferencian de la versión oficial de los hechos. Algunos han seguido un llamado literario de escribir sobre el conflicto armado como una necesidad historiográfica y como un imperativo para 
dar testimonio de los hechos de violencia. Así se desarrollaron nuevas expresiones literarias, que por ejemplo reúnen nuevas formas del testimonio y de la tradición oral (Giraldo, 2008). En este marco está inscrita la obra del sociólogo, periodista y escritor colombiano Alfredo Molano.

\section{La escritura de Alfredo Molano y la pó́tica de la escuCha}

Alfredo Molano dedicó su vida a la investigación del conflicto armado, pues desde hace más de treinta años publicó libros y columnas de opinión sobre el tema. Se podría decir que es el escritor colombiano que ha descrito las distintas dimensiones del conflicto, de una manera irreverente y polifacética, distanciándose de las instituciones como la academia o la política. El autor ha construido una versión de los sucesos de la guerra que muchas veces está en contra de las versiones oficiales que manejan las instituciones y los medios de comunicación en el país, en su mayoría controlados por élites económicas y políticas que defienden sus intereses, muchas veces por medio de la manipulación de la información y a la opinión pública (Vega, 2015). La censura y la desinformación sobre la guerra y sus causas traen como consecuencia la indiferencia de los habitantes de las ciudades frente a las víctimas del campo y, en última instancia, refuerza la impunidad de los crímenes cometidos. Además, se impide así la formación de una opinión crítica de la población en general frente a los sucesos del conflicto. En sus textos, Molano habla de las versiones del país que representan la realidad del conflicto armado: por un lado, está el país real, en el que viven los campesinos fuera de las grandes ciudades y, por el otro, el país formal, una ficción de país que desconoce la realidad del conflicto y se cree ajena a ella (Molano, 2001). En defensa del disenso y de esas otras versiones de los hechos, Molano también fue blanco de persecusiones y amenazas por parte de grupos armados ilegales, que en su momento lo llevaron a exiliarse en Europa, como está consignado en el libro propuesto para el análisis, Desterrados?

7 Comprometido con la paz y convencido de la necesidad de una transformación estructural en el país, Molano se desempeńó los últimos dos años de su vida (2018-2019) como miembro de la Comisión del Esclarecimiento de la Verdad, entidad creada a partir de los acuerdos de paz de 2016 para consolidar un informe que diera cuenta de lo sucedido en la guerra para su esclarecimiento, promover su reconocimiento y no repetición. 
Para el autor colombiano, fue crucial desde sus textos dilucidar el problema del conflicto armado a partir de sus causas como el problema por la tierra —el limitado acceso que tiene la mayoría la población a la propiedad de la tierra- y la exclusión política - las escasas posibilidades de participación política que tiene la población en general en una incipiente democracia fallida con profundos problemas de corrupción y violencia- (Zuluaga, 2001). Estas causas del conflicto se remontan a las guerras civiles desde la independencia, cuyos orígenes a su vez se encuentran en las disputas por el control del territorio y la discrepancia de los dos partidos políticos tradicionales, el Liberal y Conservador, que luego dieron lugar a La Violencia.

Sin embargo, las dimensiones de la violencia a inicios del siglo XXI se sobreponen al conflicto y sus causas, y se presenta un escenario de múltiples violencias, pues en el curso de la historia aparecieron otros factores que complejizaron las formas de violencia como el surgimiento de las guerrillas, de los grupos paramilitares y la consolidación de la economía ilegal del narcotráfico. La frontera entre la legalidad y la ilegalidad se hizo cada vez más borrosa y se instauró un clima de violencia generalizada, que pasa por la difusa violencia social, la violencia política, la violencia del crimen organizado, hasta la violencia del narcotráfico (Zuluaga, 2001).

Dentro de este panorama de múltiples violencias, la población civil ha sido la más afectada en el marco del conflicto armado, pues muchas veces ha sido puesta en el medio del fuego cruzado; ha sido víctima de numerosos crímenes, traumatizada, empobrecida y forzada a migrar a las grandes ciudades. Además de ser víctima de la violencia, el terror y el destierro, la población civil ha sido enmudecida y ha perdido la libertad pues, sobre todo en las zonas de los enfrentamientos armados (donde el territorio ha sido controlado por los actores del conflicto), la población solo ha podido sobrevivir mediante el sometimiento y el silencio (Zuluaga, 2001). La obra de Alfredo Molano está compuesta principalmente por la reunión de estas voces que han sido enmudecidas, narraciones que han surgido de sus entrevistas a las víctimas y actores de la guerra y que dan cuenta de la multiplicidad de las violencias que se han originado con el conflicto armado. 
En su devenir como autor, Molano señala su interés por las historias de la gente simple, de los campesinos víctimas del conflicto armado y en su trabajo de campo como sociólogo descubre una gran distancia entre la teoría sociológica y la realidad: "Una distancia que fue aumentando cuando me encontré con la mirada campesina, ese agujero, por donde sigo mirando al país” (Molano, 2014). De este modo, a través de sus viajes a las regiones del país y desde el contacto con la gente Molano reconoce un punto de quiebre en su experiencia, una "ruptura epistemológica"; a pesar de que el objeto de las ciencias sociales sean las personas y las relaciones sociales, el autor descubre que los métodos y el lenguaje de las ciencias está divorciado del lenguaje de la vida. Así, construye el escritor una forma de expresión propia que va más allá de lo sociológico, historiográfico y periodístico, pues da cuenta de una propuesta poética que surge o se instala en la realidad humana de los actores y sobre todo de las víctimas del conflicto armado. Se trata de una literatura que se ubica en la frontera entre literatura y periodismo, entre ficción y realidad, tensión que da cuenta de la complejidad de la sociedad colombiana. Por esto, Molano no puede ser clasificado en un género, pues los atraviesa. Sin embargo, su escritura se puede situar en el marco de la literatura que trata sobre la violencia en Colombia y del testimonio, elementos que a continuación serán brevemente reseñados para luego dar paso a la presentación de su poética de la escucha.

La llamada "literatura sobre la violencia" comprende los trabajos literarios que tematizan el conflicto armado en Colombia y que en los últimos cincuenta años han contribuido a la literalización de la historia del país (Giraldo, 2008). De unas obras que se encontraban muy cerca de los sucesos de la guerra y se caracterizaban por elementos literarios homogéneos y lineales, se fueron desarrollando nuevas formas de representación que tienden a ficcionalizar los hechos por medio de nuevos sistemas estéticos como alegorizaciones, cadenas simbólicas e imágenes significantes (Figueroa, 2004). Dos obras cruciales en estas nuevas formas de representación que constituyen el marco de la literatura sobre la violencia son La Vorágine (1924), de José Eustasio Rivera, y Cien años de soledad (1967), de Gabriel García Márquez. Según el crítico literario Felipe Martínez (2008), son obras que instauran la modernidad en la literatura, pues inauguran el mito de la historia del siglo xx en Colombia. Frente a las dimensiones de la violencia y a la imposibilidad de darle una explicación racional a las continuas guerras, el mito se convierte en la única posibilidad para 
escribir sobre la guerra. De esta manera, surge en la literatura una "metafísica de la violencia eterna" que constata la "omnipresencia de la guerra", una realidad que parece ser el destino y la maldición de una nación (Martínez, 2008). Martínez señala que autores contemporáneos como Laura Restrepo, Arturo Álape y Alfredo Molano, entre otros, recurren a una "fuga en el tiempo mítico de la literatura", que es su continuo presente. Se trata del tiempo ahistórico y cíclico, denominado el "tiempo macondiano de la violencia”, en el que los sucesos y personajes en la guerra repiten sus acciones y nombres, como el linaje dinástico en la obra de García Márquez, que sirve como metáfora de la historia colombiana en su "atemporización de una tragedia cuyos protagonistas parecen eternizarse en distintos personajes” (Martínez, 2008). Consideramos que, si bien este elemento está presente en la caracterización de la violencia que aborda Molano en su obra y que en la última parte de este escrito se evidenciará en la representación de la violencia en Desterrados, la poética del autor y sus personajes tienen una singularidad especial que desborda la descripción de Martínez.

El testimonio también ha constituido un importante género dentro la literatura sobre la violencia, que en Latinoamérica en general se difunde con el auge de los movimientos sociales y las luchas populares a partir de la segunda mitad del xx y se consolida en Colombia en los años ochenta. La literatura testimonial se destaca, entre otros aspectos, por tener un narrador en primera persona que es al mismo tiempo protagonista o testigo de los hechos que cuenta; tiene la pretensión veracidad, pues hace referencia a hechos verdaderos; a menudo es de contenido biográfico; presenta la mediación de un sujeto, muchas veces un académico, quien, en últimas, consigna la historia escrita (Figueroa, 2004).

A partir de este contexto de la literatura sobre la violencia y el testimonio como puntos de referencia de la obra de Alfredo Molano, se centrará la mirada en la poética del autor. El término poética implícita comprende obras literarias y textos poetológicos (tales como ensayos, prólogos, discursos, etc.) que revelan las reflexiones del autor frente a su comprensión personal sobre la literatura y el ejercicio de la escritura, sus efectos y proyecciones (Allkemper, 2014). 
En numerosos textos literarios y no literarios de Molano se pueden encontrar las reflexiones sobre su poética de la escucha; para él la escucha es al mismo tiempo escritura, ya que de la primera surge el acto de creación escrita. La actividad literaria y sus matices se desarrollan desde el convencimiento de que la escritura es un acto de comunicación y surge de un acto de comunicación. No se trata de un simple método de creación, sino que parte de un compromiso, es un acto ético:

Escuchar y escribir son actos gemelos que conducen a la creación. El conocimiento no es el resultado de la aplicación de unas reglas científicas sino un acto de inspiración cuyo origen me es vedado, pero cuya responsabilidad me es exigida. (Molano, 2014, párr. 11)

De esta manera, ética y estética son inseparables para el autor y atraviesan su propuesta literaria que parte de una relación humana y un compromiso con los testigos y las víctimas del conflicto, pues "crear es, al fin y al cabo, un acto ético" (Molano, 2014, párr. 12). En esta poética la creación es conocimiento y es ética, el conocimiento es entendido como parte fundamental del arte "[...] la creación es el movimiento de la vida. Por eso todo esfuerzo encaminado a conocer debe aspirar a crear, no a descubrir" (Molano, 2014, párr. 12).

En sus reflexiones poetológicas, Molano cuenta que la escritura se convirtió en una actividad obligatoria e incluso apasionante para él y generó preguntas sobre la función de sus textos. En la recepción de algunas de las narraciones por parte de sus protagonistas, el escritor descubrió que la gente se encontraba en los personajes y que la literatura cumplía así la función de un espejo:

[...] la gente llana entendía lo que yo escribía con su voz. Los colonos, los aventureros, los guerrilleros, los despojados y hasta los desaparecidos adquirían así vida textual. Entendí que los relatos podían servirles de espejo para que se reconocieran y recabaran en la fuerza que, sin saberlo, cargaban. (Molano, 2014, párr. 9) 
Después de leer los textos, podían reconocerse a sí mismos, volver a experimentar sus acciones y sentimientos a cierta distancia, cuestionarse a sí mismos o aceptarlos: Se trataba de "[el] sentido de la vida que podía exigir del conocimiento" (Molano, 2014, párr. 9). A través de la aceptación de los textos por parte de sus protagonistas, "el conocimiento encontró su objeto, cumplió su razón de ser" (Molano, 2014, párr. 9). La literatura de Alfredo Molano se presenta como una forma de conocimiento, que vuelve a su fuente, la vida.

Dentro de los elementos estilísticos de la narrativa del autor que parten de la poética de la escucha se destacan el gesto de escribir en primera persona, la elección del lenguaje popular y la construcción de personajes colectivos, que desarrollaremos a continuación.

El gesto de escribir en primera persona parte de la convicción ética de darle voz al dolor de los protagonistas del conflicto y de la historia del país, que también es una característica de la literatura testimonial. Así, Molano les otorga a las víctimas y actores de la guerra una voz de la que normalmente carecen y parte también de la necesidad de estar tan cerca como sea posible de las personas que le confiaron sus historias: "La [persona] real. Es ella la que tiene que hablar para que la palabra del escritor sea su palabra. Ello significa para el que llega, estar abierto a escuchar cada sílaba, cada coma, cada gemido" (Molano, 2015, p. 496). Este gesto, criticado por las ciencias sociales que lo han tildado de poco objetivo, le ha permitido al autor desvanecerse en los testimonios de sus personajes como un "director de orquesta" que se deja ver sin ser oído y construir una empatía con los testigos que le comparten sus historias, empatía que luego se extiende a los lectores.

Este primer elemento se presenta como ético y estético, pues parte de una decisión creativa pero también de la certeza de un compromiso por no usurpar o falsificar las voces que le fueron confiadas; sería artificial reproducir esas voces con un lenguaje científico o técnico pues "la gente no habla en conceptos a menos que quiera esconderse" (Molano, 2015, p. 496). Asimismo, encontramos una dimensión ética en el compromiso de darles a los campesinos, pobres, marginados y excluidos de la sociedad un lugar en la historia, en donde "[e]l yo de la primera persona que relata 
es al mismo tiempo el nosotros que es relatado" (Molano, 2015, p. 496). Molano apela, así, a un modo de identificación con la ajena realidad de los campesinos y logra el efecto de interpelar a los lectores, haciendo que vuelvan la mirada hacia las otras regiones de Colombia y a nuevas versiones del conflicto desde la voz de sus víctimas.

Otro elemento de la poética de la escucha en Molano es el uso del lenguaje de la gente en sus narraciones, el lenguaje popular, que es revalorizado y celebrado. Aunque socialmente sea sancionado y despreciado por no ser culto, el autor afirma: "La palabra cotidiana, la palabra oral, el lenguaje de diario, íntimo, es bello de por sí. Tiene una belleza esquiva porque ha sido sancionada como vulgar, nacida en el vulgo, o sea en el pueblo" (Molano, 2015, p. 498). Precisamente así logra rescatar la tradición oral y defiende una posición polémica al considerar, por ejemplo, el lenguaje de los sicarios como bello, pues más allá de lanzar un juicio moral sobre sus crímenes, estos poseen "una palabra encantada, plagada de figuras, de metáforas crudas, de simbolismos implícitos" (Molano, 2015, p. 498). A este respecto el autor concluye: "La belleza de la palabra cotidiana puede constituir el sumario para ser acusado de hacer literatura y no sociología” (Molano, 2015, p. 498).

Un tercer elemento de la poética de la escucha es la construcción de personajes colectivos. En estos, la frontera entre un personaje y otro es muy difusa, pues Molano desarrolla personajes prototípicos, es decir, personajes ficticios muchas veces basados en varias personas reales: "Su trayectoria no era modificada, era textual, digamos, y a través de su propio relato agregábamos - yo y él- fragmentos de otras historias como si nos las hubieran contado" (Molano, 2015, p. 495) ${ }^{8}$. En un claro acto de libertad creativa, el autor crea personajes que nos apelan igualmente como comunidad espectadora, al representar estos a una colectividad cuyos relatos empiezan a ser contados. Asimismo, la construcción de sus personajes no está sesgada por una mirada moralista que divide a los actores del conflicto en los buenos y los malos, sino que presenta un panorama mucho más complejo de la realidad que

8 Molano mismo hace referencia al uso de la imputación, un método de las ciencias sociales propuesto por Orlando Fals Borda, en el que la información de diversas entrevistas del trabajo de campo es reunida en una historia atribuida a un solo personaje creado por el investigador. 
representa el mismo: "Todo personaje es fragmentario y por tanto de alguna manera complementario de otro que ha vivido experiencias históricas similares" (Molano, 2015, p. 496).

\section{DESTERRADOS: CRÓNICAS DEL DESARRAIGO}

El siguiente apartado de este artículo se centrará en el libro de crónicas Desterrados, en el que a la luz de los elementos de la poética de la escucha se analizarán las representaciones de desarraigo y violencia que se presentan en las narraciones allí reunidas. Desterrados se publicó en 2001, cuando Molano estaba exiliado en Espańa. Es un libro sobre los desterrados del conflicto colombiano escrito por un autor que vivía al mismo tiempo la experiencia del destierro. La obra consta de ocho narraciones que contienen las historias de vida o crónicas de los desplazados internos del conflicto colombiano. También es importante destacar que las historias de Desterrados se construyen en dos niveles: por un lado, están las historias de vida de los personajes con su visión personal e íntima de los acontecimientos, y por otro lado las condiciones históricas, el contexto regional y del conflicto armado de lo narrado. El siguiente análisis de las representaciones del destierro y la violencia no trata en detalle las narraciones individuales, sino que presenta una visión general de los pasajes ejemplares en los que estos motivos aparecen.

Inicialmente, llama la atención que en esta obra el autor transite de escritor a personaje desde la experiencia de su destierro a España, y algo que es una excepción en su obra, Molano sea también el protagonista de la primera narración, "Desde el exilio", que presenta la reflexión sobre su exilio y el drama del desplazamiento forzado en Colombia. Asimismo, sirve de contexto y antesala para dar paso a los relatos testimoniales de las víctimas de la guerra, de las cuales la propia experiencia evidencia solo "un pálido reflejo" de las experiencias de las víctimas en la zona del conflicto:

Comprendí —agachando la cabeza en señal de profundo respeto- que el drama de mi exilio, a pesar de sus dolores, es un pálido reflejo de la auténtica 
tragedia que viven a diario millones de colombianos desterrados, exiliados en su propio país. (Molano, 2001, p. 23)

Aquí apreciamos cómo no solo la representación de la realidad de las víctimas juega un rol decisivo y se encuentra en el centro de su poética, sino también cómo el compromiso ético, de denunciar y dar a conocer la tragedia de los colombianos que viven confinados al destierro en su propio país, moviliza su escritura. El topos del exilio le sirve al autor, por un lado, de reflexión metodológica y, por el otro lado, al ser él mismo víctima de amenazas por su trabajo como periodista, exiliado voluntariamente, lo pone en contacto con el dolor profundo de esta experiencia deshumanizante de perder las raíces y de añorar el lugar de origen:

El exilio, a pesar de todos los dolores que ha significado, me ha enseñado a mirarle la cara a la soledad que siempre anda conmigo y a no tener más que lo que llevo puesto, para no perder la libertad de regresar a Colombia cualquier hora de cualquier día. Los sabores amargos del desarraigo cambian y a veces llegan a ser hasta agridulces, aunque hay un peso agobiante que se arrastra siempre de calle en calle, de noche a noche. (Molano, 2001, p. 22)

Yuxtapuesto a la historia del propio exilio, Molano propone como punto de partida de las narraciones de Desterrados el desarraigo como relato fundante de la historia de Colombia. Este relato converge en las experiencias individuales de los personajes, en el que se evidencia una ruptura en la humanidad de la persona, y a partir de esa ruptura las víctimas cuentan su historia. De ahí que Molano equipare la historia del desarraigo en Colombia con el relato de una mujer a la que entrevista en sus primeros años de sociólogo y quien describe su vida como una constante huída (Molano, 2001). Este relato fue a su vez crucial en el rompimiento de su escritura, que dejó de pretender ser científica: "Entendí que el camino para comprender no era estudiar a la gente, sino escucharla" (Molano, 2001, p. 14). De nuevo nos encontramos con elementos de la poética de la escucha.

La gente me contó mil cuentos. En todos había y hay un elemento común: el desalojo por razones políticas, pero con fines económicos. A los campesinos 
los acusaban los ricos de ser liberales, o conservadores, o comunistas, para expulsarlos de sus tierras y quedarse con ellas. Siempre las guerras se han pagado en Colombia con tierras. Nuestra historia es la historia de un desplazamiento incesante, solo a ratos interrumpido. (Molano, 2001, p. 14)

El destierro como relato fundante en la historia de Colombia le permite a Molano representar esta tragedia humana y contextualizar el problema de la tierra como una de las razones del conflicto armado, abordando su complejidad histórica. El destierro se traduce al mismo tiempo en un lugar donde el ser humano no logra reconocerse a sí mismo, pues desde este nuevo espacio y en medio de la desesperanzadora situación, su identidad se ve coartada. Lo que le daba sentido a la existencia ya no está: la tierra y los seres queridos. Los desterrados muy difícilmente pueden superar tanto el trauma de la pérdida de sus tierras, como de la muerte de sus seres queridos. Sin embargo, Molano también relata un recurso posible en esta situación, la posibilidad de "fundarse" de nuevo y de convertir la narrativa del dolor y el desarraigo, de la pérdida de las raíces en un lugar para la resiliencia y la reconciliación con el nuevo escenario:

Los círculos que el exilio traza y recorre a diario son estrechos; se tiene ese miedo que los marineros antiguos le tenían al abismo, un miedo que encierra e impone una insoportable redundancia a los pasos. Tengo la certeza de que es la misma sensación que experimentan los colonos en las soledades de la montańa, y que poco a poco van derrotando a punta de rula, ganando terreno para cosechar y sobre todo para mirar bien lejos y saber quién llega. Como los colonos, fui también "fundándome», haciendo las paces con las paredes del apartamento, con las esquinas del barrio, con las calles de Barcelona, hasta que caí en cuenta de que ellas nunca me habían declarado la guerra. (Molano, 2001, p. 23)

La representación de la violencia en la obra Desterrados es la segunda temática que me propongo abordar para cerrar este segmento. Como se explicó en la parte anterior de este trabajo, la violencia se ha convertido en una categoría histórica de Colombia, pues en marco del conflicto armado se presentó una situación de interacción de múltiples 
violencias (Zuluaga, 2001); estas alcanzaron proporciones tan extremas que escapan a los intentos de explicación racional. Alfredo Molano presenta una caracterización particular de la violencia en la crónica "Desde el exilio" de la siguiente manera:

En Colombia casi todo campesino puede decir que su padre, o su tío, o su abuelo fue asesinado por la fuerza pública, por los paramilitares o por las guerrillas. Es la diabólica inercia de la violencia, que, desde antes de 1948, año del asesinato de Gaitán, ha dejado más de un millón de muertos. (Molano, 2001, p. 13)

A través del mito de la violencia eterna, retomando a Martínez (2008), la violencia es representada como espiral sin salida, pues el conflicto ha llegado a casi todos habitantes rurales del país. Molano le atribuye una "diabólica inercia" a la violencia. Esta afirmación contiene una contradicción porque existe una tensión semántica entre los dos términos, que normalmente son contradictorios: violencia e inercia. La semántica de la violencia incluye movimiento, energía, fuerza, vigor, etc. Por el contrario, la inercia hace referencia a la rigidez y al letargo. Esta cualidad puede estar relacionada con el hecho de que la violencia cotidiana y el anonimato de las víctimas rurales a nivel nacional han creado pasividad e indiferencia por parte de la población en general (Grupo de Memoria Histórica, 2013). Pareciese que los colombianos se han acostumbrado a la violencia como si fuera algo normal.

La imagen de la "diabólica inercia de la violencia" también hace alusión a la repetición constante de los ciclos de violencia en Colombia, que tiene sus inicios incluso antes del asesinato de Gaitán. En el fondo, los actores del conflicto siguen siendo los mismos, quienes se enfrentan en el campo de batalla, guerrilleros, paramilitares y soldados son en su mayoría hijos de campesinos pobres, quienes ha puesto su vida en más de cinco décadas de conflicto. Los políticos y jefes también siguen siendo los mismos, o más bien, se perpetúan en el poder por medio de su descendencia. En la inercia de la violencia también encontramos el tiempo macondiano de la violencia (Martínez, 2008), la representación alegórica de la famillia Buendía en García Márquez, que hace alusión a las víctimas y actores de los enfrentamientos armados, que están condenados a generaciones tras generaciones de muerte. Los personajes 
de Desterrados no escapan tampoco a la espiral de la violencia y desde la óptica de las víctimas, cuentan cómo no han podido dejar de huirle a la violencia, que los persigue como una maldición de la que no pueden salir. En "El barco turco", Toñito cuenta su historia de desarraigo y persecución después de la masacre perpetrada en su pueblo, donde perdió a sus familiares y conocidos, que parece ser también una violencia que lo persigue:

En el Mandela hay miles de familias. Todos han llegada de huida, dejando el camino de los muertos. Pero quieren seguir viviendo y les toca aceptar la vida como viene. Uno no puede ponerse a regatear con el destino cuando le ha visto la cara a la muerte. [...] Cuando llegué al Mandela lo primero que pensé era que los diablos que acabaron con mi pueblo debían de andar por ahí. Pero también me dije que era imposible que aquí, en medio de tanta gente, nos fueran a rematar. (Molano, 2001, p. 86)

"La arbitrariedad y el absurdo fundamentales" de la violencia desarrollados por Hannah Arendt (2015) puede aplicarse a la situación sin salida de las formas de violencia en Colombia. La impotencia del Estado y la debilidad de sus instituciones encuentran consonancia con su argumentación: "La violencia desnuda ocurre donde se pierde el poder" y en la afirmación: "Políticamente es crucial que la pérdida de poder conduzca más probablemente a la violencia que a la impotencia, como si esta pudiera sustituir al poder perdido [...]"' (Arendt, 2015, p. 9). A través de la represión, el Estado colombiano y las élites dificultaron la participación política de la población y la repartición justa de la tierra. A medida que los civiles tomaban conciencia de sus derechos, la falta de poder del sistema es sustituida por la violencia, que desencadenó a su vez múltiples formas de violencia. En las historias de Desterrados, encontramos muchas de ellas: violencia por parte de grupos guerrilleros y paramilitares, ausencia de instituciones estatales, corrupción en la Policía y el Ejército, violencia contra las demandas de los pequeños agricultores por salarios o precios justos para sus productos agrícolas. Muchas veces las instituciones estatales tampoco protegen la vida de los pequeños agricultores, ya que a menudo ellos mismos son vistos como una amenaza. La figura de Osiris en la crónica del mismo nombre atestigua este hecho al decir

9 Traducción propia. 
que su hijo fue asesinado por el ejército y que ella junto con su familia está siendo perseguida por esta verdad:

\begin{abstract}
¿A quién reclamarle justicia si la misma ley que mata es la que levanta los muertos? ¿Dónde poner el denuncio si toda autoridad está untada de sangre? La misma ley que toma las medidas y hace los exámenes para decir quién es el asesino, es la misma que cometió el crimen. (Molano, 2001, p. 139)
\end{abstract}

El origen de esta inercia de la violencia se encuentra también en el hecho de que las diferencias políticas en Colombia no son aceptadas ni respetadas. Hay una especie de rigidez en la mentalidad política, el contrario político es visto como un enemigo que debe ser destruido porque tiene una opinión diferente. Los conflictos entre pequeños agricultores y grandes terratenientes, grupos armados legales o ilegales no permiten el diálogo, sino solo la confrontación con el uso directo de la fuerza. Todas las crónicas en Desterrados llaman la atención sobre esto, porque los paramilitares y las guerrillas son despiadados en sus tratos con las personas de las que sospechan; colaboran con la contraparte. Ejemplo de ello lo encontramos en "El jardín", donde Ninfa cuenta cómo su marido fue asesinado por la guerrilla. Este grupo exigía impuestos sobre las ganancias de su plantación de amapola. Sin embargo, los paramilitares se le adelantaron y recogieron el dinero, lo que le costó la vida a Álvaro:

No perdono a la guerrilla. No le perdonaré nunca no haber investigado ni averiguado nuestra equivocación. Nosotros actuamos de buena fe. Los paracos nos engañaron y, lo peor, los engañaron también a ellos y los llevaron a cometer un crimen. Porque asesinaron a un inocente por el puro miedo, por estar acostumbrados a creer que siempre tienen la razón y que su palabra nadie la discute. Eso será con sus soldados, pero no les puede funcionar con gente de civil que no está con ellos, que no se ha uniformado. Se dejaron engañar de los paracos. No he podido entender cómo pueden matar a una persona sin darle la oportunidad de hablar. (Molano, 2001, p. 112)

Finalmente, la representación de la violencia en Desterrados nos permite comprender la necesidad imperante de la comunicación y el diálogo como una clave que finalice 
el ciclo de la violencia. En últimas, es esa posibilidad de hablar a la que Ninfa hace referencia, la que el escritor por medio de sus crónicas posibilita, pues le "da la oportunidad de hablar" a las víctimas, y evidencia lo absurdo de las dinámicas de la guerra y su deshumanización, pero, sobre todo, da cabida a nuevas narrativas del conflicto, validando la poética de la escucha que presta oído, pero también voz desde nuevos lugares de enunciación.

\section{Epílogo}

A partir del carácter esencial del arte en la vida humana se argumentó en este escrito el posible rol de la literatura en el escenario del posconflicto: generar una forma especial de compasión que lleve a asumir como sociedad la corresponsabilidad de la violencia y, como la literatura alemana de la posguerra, contribuir de manera decisiva al trabajo de la memoria y la superación de sesenta años de violencia, violaciones de los derechos humanos y crímenes contra la humanidad.

Se puede decir que los alcances de la poética propuesta por Alfredo Molano y su tratamiento del conflicto armado le confieren la posibilidad de humanizar del conflicto y sus relatos, pues el autor le pone rostro a las víctimas, quienes recuperan su voz por medio de su escritura. Por otro lado, esta escritura se inserta en los procesos de superación del duelo y del trauma que ocasionaron en las víctimas los sucesos del conflicto armado y, no menos importante, les permite no solo a las víctimas, sino a la población colombiana en general construir una memoria colectiva sobre la violencia que con suerte se convertirá en una memoria histórica a través de la que sea posible superar las violencias que continúan y construir la paz.

Igualmente se procuró demostrar cómo la obra de Molano representa una piedra angular en la construcción de memoria en el país mediante su extenuante narración del conflicto, pues la literalización de la realidad comprende una de las posibilidades de construcción de memoria. Su trabajo muestra que el diálogo entre los grupos sociales opositores es necesario y posible si se está dispuesto a mirar la crisis colombiana desde diferentes ángulos. Esto permitirá una presentación más completa 
de la realidad y una base más amplia de discusión para una convivencia pacífica del pueblo colombiano.

Otras preguntas que esta investigación no abordó y que valdría la pena investigar son la recepción de los textos de Alfredo Molano por parte de otros actores y víctimas del conflicto armado que no hayan sido sus entrevistados y de la población colombiana que no ha vivido de cerca el conflicto armado, así como la función pedagógica de este tipo de literatura y sus alcances.

\section{REFERENCIAS}

Adorno, T. (2012). Jene zwanziger Jahre. En P. Kiedaisch (comp.). Lyrik nach Auschwitz? Adorno und die Dichter (pp. 49-52). Stuttgart: Reclam.

Allkemper, A. (2014). Literaturwissenschaft. Paderborn: Fink.

Arendt, H. (2015). Macht und Gewalt. München: Piper Verlag.

Baer, U. (comp.) (2000). Niemand zeugt für den Zeugen: Erinnerungskultur und historische Verantwortung nach der Shoah. Frankfurt: Suhrkamp.

Figueroa, C. (2004). Gramática-violencia: Una relación significativa para la narrativa colombiana. Tabula Rasa, (2), 93-110.

Fischer, E. (1967). Von der Notwendigkeit der Kunst. Hamburg: Claassen.

Giraldo, L. (2008). Narradores colombianos y escrituras del desplazamiento. Indicios y pertinencias en una historia social de la literatura. Revista Iberoamericana, 77(223), 423-439.

Grupo de Memoria Histórica (2013). ;Basta Ya! Colombia: Memorias de guerra y dignidad. Bogotá: Imprenta Nacional. 
Hartman, G. (2000). Intellektuelle Zeugenschaft und die Shoah. En U. Baer (comp.) Niemand zeugt für den Zeugen: Erinnerungskultur und historische Verantwortung nach der Shoah (pp. 35-52). Frankfurt: Suhrkamp.

Heidegger, M. (2001). Arte y poesía. México D.F.: Fondo de Cultura Económica.

Kiedaisch, P. (comp). (2012). Lyrik nach Auschwitz? Adorno und die Dichter. Stuttgart: Reclam.

Laub, D. (2000). Zeugnis ablegen oder Die Schwierigkeiten des Zuhörens. En U. Baer (comp.), Niemand zeugt für den Zeugen: Erinnerungskultur und historische Verantwortung nach der Shoah (pp. 68-83). Frankfurt: Suhrkamp.

Martínez, F. (2008). La fuga al mito Laura Restrepo y Alfredo Molano: El cronista colombiano y la tradición literaria nacional. LL Journal.

Molano, A. (2001). Desterrados: crónicas del desarraigo. Bogotá: El Áncora Editores.

Molano, A. (2014). Vaya, mire y me cuenta. Discurso en la entrega del doctorado Honoris Causa de la Universidad Nacional de Colombia. Consultado en https://blogs.elespectador.com/cultura/el-magazin/alfredo-molano-bravo-palabras-honoris-causa.

Molano, A. (2015). La gente no habla en conceptos a menos que quiera esconderse. En V. M. Moncayo (comp.), Antología del pensamiento crítico colombiano contemporáneo (pp. 491-500). Buenos Aires: Clacso.

Schadewaldt, W. (1967). Das Wort der Dichtung. En M. Buber y C. Podewils (eds.), Sprache und Wirklichkeit. Essays. München: Deutscher Taschenbuch Verlag.

Schnurre, W. (2012). Dreizehn Thesen gegen die Behauptung, daß es barbarisch sei, nach Auschwitz ein Gedicht zu schreiben. En P. Kiedaisch (comp.). Lyrik nach Auschwitz? Adorno und die Dichter (pp. 123-125). Stuttgart: Reclam. 
Torres Duque, O. (1998). Violencia y narración en Alfredo Molano. Boletín Cultural y Bibliográfico, 47, 24-41. Consultado en https://bit.ly/2TYh6lu.

Vega, R. (2015). El pensamiento crítico en un mundo incierto. En: V. Moncayo (Comp.) Antología del pensamiento crítico colombiano contemporáneo (pp. 433-449). Buenos Aires: Clacso.

Zuluaga, J. (2001) Annäherung an die Dynamik von Krieg und Gewalt. En S. Kurtenbach (comp.). Kolumbien zwischen Gewalteskalation und Friedenssuche. Möglichkeiten und Grenzen der Einflussnahme externer Akteure (pp. 15-35). Institut für Iberoamerika-Kunde. Frankfurt: Vervuert. 